\title{
DE IURI LOTMAN A BERTRAND WESTPHAL: HACIA UNA REPRESENTACIÓN MULTIFOCAL DE LAS CULTURAS
}

\author{
From Yuri Lotman to Bertrand Westphal: Towards a Multifocal Representation \\ of Cultures
}

\section{RESUMEN}

La presente contribución pretende recorrer y explorar el anticipatorio aporte del semiólogo y teórico de la literatura Iuri Lotman al llamado giro espacial y, en particular, al enfoque geocrítico. Tomando en cuenta las palabras de Bertrand Westphal, según el cual "la geocrítica está muy presente en el análisis de las supuestas áreas 'periféricas', el que contribuye a relativizar la 'marginalidad'" (Westphal 2015: 126), se buscará aquí poner énfasis en la visión espacio-textual de Lotman y su relación inseparable con el concepto semiótico-literario y cultural de frontera y espacio "propio-ajeno" — visión que da como resultado lo que el académico francés llamaría una representación multifocal de la realidad.

Palabras claves: Lotman, geocrítica, semiótica cultural, fronteras, de-marginalización.

\section{UNIVERSUM}

Revista de Humanidades y Ciencias Sociales

\section{LAURA GHERLONE.}

Centro de Estudios de Literatura Compara "M. T. Maiorana",

Facultad de Filosofía y Letras, Universidad Católica Argentina, Argentina.

Correo electrónico: laura.gherlone@ gmail.com

ORCID: 0000-0002-0117-1077

ResearchGate: Laura Gherlone

Scholar.google:https://scholar.google.it/ citations? user $=6$ HVHKkgAAAAJ\&hl=it Academia.edu: LauraGherlone

Artículo recibido el 3 de diciembre, 2019. Aceptado el 2 de marzo, 2020.

Web: http://universum.utalca.cl | ISSN: 0716-498X - 0718-2376 


\begin{abstract}
This paper aims to explore the farseeing contribution of the semiotician and literary theorist Yuri Lotman to the so-called spatial turn and, in particular, to the geocritical perspective. Taking into account Bertrand Westphal's words, according to whom "geocriticism is well present in the analysis of supposedly 'peripheral' areas, which contributes to relativize the "marginality"' (Westphal 2007b: 329), emphasis will be placed here on Lotman's spatialtextual vision and its close relation with the semiotic-literary and cultural concept of boundary and "own-alien" space — vision resulting in what the French scholar would call a multifocal representation of reality.
\end{abstract}

Keywords: Lotman, geocriticism, cultural semiotics, boundaries, de-marginalization

\title{
PENSAR ESPACIALMENTE LA CULTURA Y SUS TEXTOS
}

El texto fundacional de Bertrand Westphal, La géocritique: réel, fiction, espace (2007a), se articula y desarrolla sobre tres conceptos clave que el académico francés ya había, en parte, explorado en su ensayo publicado poco tiempo antes y titulado "Pour une approche géocritique des textes" (Westphal 2000, ${ }^{1}$ traducción española en García, Punte y Puppo 2015)—, es decir, la espacio-temporalidad, la transgresividad y la referencialidad. En la presente contribución, nacida en el marco del proyecto de investigación interdisciplinaria "Espacios e interacciones culturales: proyecciones latinoamericanas de la Geocrítica", 2 quisiera verificar si y cómo el semiólogo y teórico de la literatura Iuri Lotman puede haber contribuido a este horizonte de pensamiento, enfocándome en particular en la noción de transgresividad.

1 El ensayo ha sido publicado también en 2005 en la revista en línea Vox poética.

2 La investigación pretende ser interdisciplinaria precisamente porque hace referencia al llamado giro espacial, movimiento de pensamiento que ha hecho converger diferentes disciplinas hacia el dónde, además del cuándo, del actuar humano.

El foco en el espacio - comenta el urbanista y geógrafo estadunidense Edward Soja — "ha irrumpido en la escena académica a mediados de la década de 1990" y se ha mostrado como el "intento de desarrollar un equilibrio más creativo y críticamente efectivo de las imaginaciones espaciales/geográficas y temporales/históricas". Las ciencias humanas y sociales como las naturales han paulatinamente reconocido la naturaleza espacial - y no solo temporal - del conocimiento, adoptando términos (a veces con carácter metafórico) tales como "mapeo, regiones, lugar, espacio, territorio, localización, geografía, cartografía" (Soja 2009: 23, 12, 25, trad. mía). 
Se trata, por supuesto, de una contribución inconsciente ya que Lotman desarrolla las ideas que expondré a continuación a partir de los años sesentasetenta $^{3}$ — también debido al universo histórico-geográfico donde vivió (véase Clowes 2011) — y, con mayor énfasis, entre mediados de los ochenta y 1993, ${ }^{4}$ es decir, antes de la masiva adopción en las humanidades del espacio como trasfondo interpretativo de la realidad.

La visión lotmaniana se inscribe, intuyéndola y anticipándola, en esa atmósfera y percepción de cambio conocida como giro espacial, presente in nuce desde los años sesenta en la ciencia geográfica: un rastro que ha marcado globalmente la evolución del pensamiento humano contemporáneo y dentro del cual confluyen, no causalmente, los actuales estudios geocríticos y ecocríticos (véase Tally Jr. 2011 y 2017, Westphal 2016), ya que

[...] el giro espacial se ha desplegado en estrecha relación con los estudios culturales críticos, prestando particular atención a pensadores postcoloniales espacialmente sensibles, tales como Edward Said, Gayatri Spivak, Homi Bhabha y Arjun Appadurai. Las conexiones con los estudios culturales también han permitido que el pensamiento espacial crítico pudiera extenderse a la antropología y la nueva etnografía, a las críticas feminista y antirracista, a los estudios sobre los medios y la comunicación, a la literatura comparada y la crítica literaria, incluyendo áreas especializadas como la novela y la poesía escritas por mujeres latinas. (Soja 2009: 25, trad. mía).

En Lotman, como se ha mencionado antes, podemos solo vislumbrar un aporte "profético" a este conjunto interdisciplinario de experiencias intelectuales espacio-centradas y, en particular, a la geocrítica; sin embargo, eso se vincula estrechamente con la idea subyacente de que el espacio es, como

3 Véase Lotman 1992a[1965], 1992b[1968], 2000b[1974]; Lotman et al. 2006[1973]).

En el presente texto, con respecto a las citas procedentes de los escritos de Lotman, se ha favorecido la versión en lengua española, cuando existe. En caso contrario, se ha adoptado la versión original en lengua rusa. En el caso específico de Lotman (1990), se trata de una monografía publicada antes en inglés y en un segundo momento en ruso (Lotman 2000a[1996]) y se ha decidido trabajar sobre ambas versiones.

4 Este periodo corresponde a la reflexión lotmaniana sobre el espacio-tiempo cuatridimensional en un sentido estético y literario, y la crítica de la idea filosófica de progreso sin fin (véase Gherlone 2014). 
subrayan Barney Warf y Santa Arias (2009: 1, trad. mía), "una construcción social relevante para la comprensión de las diferentes historias de los sujetos humanos y para la producción de los fenómenos culturales".

La contribución de Lotman es, en cambio, acogida de manera consciente por Westphal, que cita al pensador ruso en varias ocasiones, mencionándolo precisamente en la introducción a La géocritique: réel, fiction, espace para recordarnos cómo el espacio geográfico en los textos siempre vehicula una atribución de significado - Westphal la llama "une lecture symbolique"(2007a: 9) - que lo trasciende. El pensador francés hace referencia en particular a la noción de semiosfera, propuesta por Lotman en 1984 y retomada extensamente en la monografía Universe of the Mind: A Semiotic Theory of Culture (Lotman 1990): es aquí donde él identifica definitivamente la relación mutua entre el espacio y la cultura, es decir aquella esfera compuesta por diversos niveles de sentido que hacen comprensible, interpretable, representable y traducible la realidad percibida. En la visión lotmaniana el espacio no es simplemente dado, sino que es una fuerza que solicita continuamente al sujeto humano (individual y colectivo), quedando así sometida a una incesante actividad de significación y representación sociales. En otras palabras, es una especie de materia activa y moldeable que los individuos plasman semióticamente atribuyéndole significados culturales distintos (extra-espaciales o simbólicos) — significados rastreables en los textos, sobre todo literarios (Lotman 1990: 150), y en las prácticas cotidianas consideradas como textos-.${ }^{5}$ De esta manera, el espacio se convierte en un lenguaje modelizante que es al mismo tiempo universal y particular, compartido y subjetivo, establecido y renegociable. Existe, comenta Lotman (1990: 191; 2000a [1996]: 320, trad. mía),

[...] un principio importante del pensamiento cultural humano: el espacio real se convierte en una imagen icónica (иконический образ, ikonicheskii obraz) de la semiosfera, es decir el lenguaje en el que se expresan varios significados extraespaciales, y la semiosfera, a su vez, transforma a su imagen y semejanza el mundo espacial real que rodea al ser humano. ${ }^{6}$

5 Para un estudio sobre los conceptos de texto y textualidad en Lotman véase Semenenko (2012).

6 La cita ha sido tomada de la monografía rusa Vnutri mysliashchij mirov (Dentro de los 
El espacio es además pluridimensional, ya que incluye tanto los microcosmos, como la casa —el lugar de la cotidianidad que da forma a la biografía individual-, cuanto las configuraciones más amplias, como la ciudad, con sus mapas normativos y sus prácticas de reinvención del paisaje urbano (véase Pilshchikov 2015), hasta llegar a la cultura en su conjunto, con su visión del espacio no-semiótico (enfoque que será expuesto en el próximo párrafo). Cabe destacar que un concepto clave en Lotman es el de vida cotidiana o modo de vida (быт, byt), ${ }^{7}$ el cual, a través de estrategias semióticas de apropiación del espacio-tiempo, perpetra y, al mismo tiempo, genera nuevas formas culturales ligadas al mundo de la literatura, la moda, la comida, la etiqueta, el baile, los objetos de uso diario, etc. El hogar, en particular, con sus representaciones simbólicas-textuales vinculadas a la distribución de los espacios, a la arquitectura y a la posición en la topografía urbana (es decir, a la relación con el mundo "externo"), se convierte en un lugar central para investigar sobre la semiótica de la cultura (Lotman 2000b[1974], 2005[1986], 2000c[1987], 1990). En esta perspectiva, el sujeto humano no solo produciría la historia, sino que generaría también la geografía (humana).

Aquí podemos vislumbrar en Lotman, de forma incipiente, una reflexión

mundos pensantes) —correspondiente a la edición en inglés antes mencionada (Lotman 1990) - y perteneciente a un escrito editado anteriormente, es decir "Dom v Mastere $i$ Margarite" (La casa en El maestro y Margarita). Este último, junto a otro escrito, "Puteshestvie Ulissa v Bozhestvennoi komedii Dante" (El viaje de Ulises en la Divina comedia de Dante), forma parte del ensayo "Zametki o judozhestvennom prostranstve" (Notas sobre el espacio artístico), publicado en 1986 en la revista Trudy po znakovym sistemam y, especificadamente, en el número XIX dedicado a "Semiotika prostranstva i prostranstvo semiotiki" (La semiótica del espacio y el espacio de la semiótica).

En aquel período el catedrático ruso estaba trabajando sobre la mutua relación entre la fuerza modelizante del espacio geográfico en los textos artísticos (literarios) y, paralelamente, sobre la energía simbólica transformadora de la semiosfera sobre el mundo percibido. Esta problemática tiene un lugar central en el pensamiento de Lotman, tanto es así que su último ensayo largo se titula "O 'realizme' Gogolia" (Sobre el 'realismo' de Gógol') en Lotman (1997[1993]): una continuación-herencia de "Problema judozhestvennogo prostranstva v proze Gogolia" (El problema del espacio artístico en la prosa de Gógol') en Lotman (1992b[1968]).

7 Se trata, escribe Silvia Burini, de una "expresión rusa prácticamente intraducible, que indica nuestra experiencia de vida cotidiana" (Burini 2017: 9. trad. mía). En inglés se traduce con "day-to-day life at home" or "everyday life". 
hoy en auge en varios trabajos pertenecientes a los estudios culturales y poscoloniales (véase por ejemplo Zivkovic 2017), los cuales han subrayado la importancia heurística de los espacios de la vida cotidiana como rastros de los afectos, las percepciones corporales, los recuerdos personales y la memoria cultural, los traumas individuales y colectivos.

Tomando las palabras de Soja (2009: 11, trad. mía), podríamos definir a Lotman como un "espacializador" (spatializer), es decir un pensador

[...] que cree no solo que el espacio es importante, sino que es una fuerza existencial vital que moldea nuestras vidas, un aspecto influyente de todo lo que alguna vez fue, es o será, una forma transdisciplinaria de ver e interpretar el mundo, la cual es tan penetrante y reveladora como la del historiador.

Veremos ahora cómo la mirada "espacializante" de Lotman se traduce en una reflexión sobre el interior y el exterior de la semiosfera en clave ética e intercultural.

\section{LA TRANSGRESIVIDAD O SOBRE LA CONCIENCIA CREADORA. ESPACIO, FRONTERAS, EXTRAÑEZA, NUEVAS PERSPECTIVAS SOBRE EL "OTRO"}

La transgresividad es una de las ideas más intrigantes de la obra geocrítica de 2007. Westphal la introduce volviendo sobre el significado de la palabra límite para los antiguos. Es limes - la línea divisoria o el trazado fronterizo entre el territorio propio (depositario del orden de la cultura) y extranjero- pero también limen, el umbral o la entrada al lugar familiar, la membrana porosa que invita a ser cruzada: ${ }^{8}$ dos acepciones en las cuales es

8 Esta doble función del límite ha sido abordada también por Lotman en el ensayo sobre la semiosfera (1996b [1984]) y en la monografía Universe of the Mind. Comenta el pensador ruso: "los puntos 'más calientes' de los procesos de formación del sentido corresponden a los límites de la semiosfera. El concepto de límite es ambiguo. Por un lado, divide, por otro, conecta. Es siempre la frontera con algo y, por lo tanto, pertenece a ambas culturas fronterizas, a las dos semiosferas adyacentes. El límite es bilingüe y plurilingüe. El límite es un mecanismo para traducir los textos de la semiótica ajena en 'nuestra' lengua, es un lugar de transformación de 
inherente una tensión marcadamente humana al plasmar simbólicamente el espacio. Recurriendo al valor polisémico de la palabra límite, Westphal nos recuerda que la transgressio implica una relación donde un sujeto (individual o colectivo) quiere penetrar en un territorio respecto del cual se encuentra en los márgenes, en el umbral (en un sentido tanto físico cuanto ideológico), reclamando a través de su presencia la necesidad del distinto, del heterogéneo:

[...] la transgresión reside por naturaleza en la interacción. (...) La transgresión interviene cuando se vislumbra una alternativa a la línea recta del tiempo, a las figuras demasiado geométricas del espacio disciplinado. (...) la transgresión impone lo heterogéneo... (Westphal 2007a: 75, trad. mía)

Según el académico francés, hoy resulta pertinente recuperar y reconsiderar este concepto antropológicamente originario - la transgresióna la luz de la posmodernidad, o sea de un mundo que ha perdido tanto la "línea recta del tiempo" cuanto el "espacio disciplinado": un mundo permanentemente heterogéneo, marcado por el surgimiento de un supra-espacio que trasciende los trazados fronterizos, haciendo encontrar cosmovisiones hasta hace poco impenetrables entre ellas, y un tiempo que se expande y se coagula, perdiendo su linealidad. En este mundo que legitima las discrepancias, la idea de relación inherente al acto de translimitar cambia: la transgresión, escribe Westphal (2007a: 81, trad. y énfasis míos),

lo 'externo' en 'interno', es una membrana filtrante que transforma los textos ajenos para que se incorporen a la semiótica interna de la semiosfera, sin dejar de ser extraños (инородный, inorodnyi). En la Rusia de Kiev había una manera de indicar a los nómadas que se asentaron en las fronteras de la tierra rusa. Se convirtieron en agricultores y, al establecer alianzas con los príncipes rusos, marcharon juntos en contra de sus compatriotas nómadas. Se les llamaba 'nuestro poganyi' (poganyi significa 'pagano' y 'de los otros', 'incorrecto', 'sin Dios'). El oxímoron 'nuestro poganyi' expresa muy bien la situación fronteriza” (1990: 137; 2000a [1996]: 262, trad. y énfasis míos). 
[...] corresponde al cruce de un límite más allá del cual se extiende un margen de libertad. Cuando se transforma en un principio permanente, se convierte en transgresividad. La mirada transgresora se dirige constantemente hacia un horizonte emancipador con respecto al código y al territorio que le sirve de 'dominio' (...). Pero la transgresión está también en el intersticio, en la nueva trayectoria, imprevista, impredecible. Es centrífuga, porque huye del corazón del sistema, el espacio de referencia.

En la visión de Westphal la transgresión ya no es una excepción (una infracción, una excentricidad, una irrupción) sino la parte viva, vibrante y "normal" de la realidad.

El discurso literario estuvo entre las primeras manifestaciones del pensamiento contemporáneo que intuyó y expresó este cambio. En la literatura rusa piénsense, por ejemplo, en un escritor como Mijaíl Bulgákov - "una mente poéticamente alucinada", como lo definió el poeta Eugenio Montale-, quien en la conocida novela El maestro y Margarita (2015[1966-1967]), jugando precisamente con los espacios, permite que lo impredecible (la trascendencia) irrumpa en la realidad y cambie "las reglas del juego", mostrando toda la irracionalidad de un sistema estatal-burocrático que quería hacerse pasar por una geometría perfecta. No por casualidad el discurso alegórico inherente a la novela le costó al escritor ruso la "mutilación" de su obra, publicada en forma parcial en 1966-1967 e integralmente solo en 1973.

El concepto de transgresividad en el campo literario arroja luz precisamente sobre aquellos que, como Bulgákov, escriben desde la perspectiva del intersticio, lejos — para retomar las palabras de Westphal— del corazón del sistema. Es esta permanente tensión entre centro y periferia, homogéneo y heterogéneo, dominante y marginal que nos introduce a la semiótica espacial de Iuri Lotman.

El semiólogo ruso trata este tema a lo largo de su parábola intelectual de cuarenta años. Para la presente contribución, quisiera ofrecer algunas consideraciones tomadas de un ensayo de 1983, disponible en traducción castellana, "Para la construcción de una teoría de la interacción de las culturas (el aspecto semiótico)" en Lotman (1996a[1983]) —un ensayo que ya está 
afectado por la reflexión sobre la llamada semiosfera, que poco después habría aparecido en forma de publicación (Lotman 1996b[1984]).

En el ensayo de 1983 Lotman se enfoca en el concepto de interacción - también central en Westphal- para indicar la condición básica de la dinamicidad de la cultura. El semiólogo ruso parte del supuesto de que la cultura tiende a definirse a través de características específicas, marcadamente espaciales, que le confieren una fisonomía y una unidad estructural. La autodefinición puede traer consigo dos tipos de problemas: por un lado, el excesivo énfasis por contraste con lo que la cultura no es (es decir, en el "bárbaro", como lo ha definido Lotman en otro lugar); por otro lado, el riesgo de convertirse en "un sistema completamente aislado (...) y estático" (Lotman 1996a[1983]: 71), donde prevalece la unificación y la homogeneidad de los códigos en vista de una compresión mutua inequívoca (взаимопонимание, vzaimoponimanie).

Para evitar que se realice esta situación a la larga destructiva, él enfatiza que la interacción con textos externos y extraños se convierte en una condición sine qua non. Es una extrañeidad que emerge tanto dentro de la cultura dada, en sus periferias (piénsese en las literaturas surgidas en el idioma y la tradición del "propio" país colonizador, con todo el "mestizaje” lingüístico que sigue) así como con respecto a otra cultura, con las inevitables dificultades (pero también los fascinantes desafíos) de la traducción intercultural e interlingüística. Lotman escribe:

El desarrollo inmanente de la cultura no puede realizarse sin la constante afluencia de textos de afuera. Al mismo tiempo, este 'de afuera' por sí mismo tiene una compleja organización: es tanto el 'de afuera' de un género dado o de una determinada tradición dentro de una cultura dada, como el 'de afuera' del círculo trazado por una determinada línea metalingüística que divide todos los mensajes dentro de una cultura dada en culturalmente existentes ('elevados', 'valiosos', 'cultos', 'de tiempos inmemoriales', etc.) y culturalmente inexistentes, apócrifos ('bajos', 'no valiosos', 'extraños', etc.). Por último, lo constituyen también los textos ajenos venidos de otra tradición nacional, cultural, de área. (Lotman 1996a [1983]: 71, énfasis mío) 
Este encuentro entre cultura y heterogeneidad conlleva dos consecuencias. En primer lugar, resulta en una representación multifocal de lo que llamamos "cultural", ya que hay múltiples puntos de vista que entran en juego - una visión que nos recuerda a Westphal cuando dice que "la geocrítica está muy presente en el análisis de las supuestas áreas 'periféricas', el que contribuye a relativizar la "marginalidad"' (Westphal 2015: 126). En segundo lugar, fructifica en lo que Lotman llama la "conciencia creadora" (творческое сознание, tvorcheskoe soznanie), es decir, ese acto que puede tener lugar tanto a nivel individual como colectivo y que considera la diferencia no solo ineludible, sino incluso necesaria. ¿Y por qué sería necesaria? Porque el encuentro con la diferencia, con el otro, con el partenaire - sugiere Lotman, anticipando el concepto de transgresividad en Westphal y convirtiéndose en un pensador filosóficamente vinculado a la llamada ética de la alteridad- es lo que garantiza la novedad dentro de un sistema, junto, pero no siempre, con la indeterminación y lo inesperado (неожиданность, neozhidannost') (Lotman 1996a[1983]: 75). Esto sucede sobre todo cuando los "códigos dominantes" no logran traducir, o sea descifrar y asimilar/convencionalizar la novedad.

Es interesante observar cómo Lotman retoma esta idea diez años después y asigna a la intraducibilidad un rol prioritario, generador de explosiones culturales, considerando de esta manera lo inesperado, es decir la impredecibilidad, una condición para nada excepcional. No es una coincidencia que su última monografía póstuma tome el nombre de Nepredskazuemye mekhanizmy kul'tury (Los mecanismos impredecibles de la cultura, 2010) donde el adjetivo nepredskazuemyi (непредсказуемый) contiene la raíz del verbo decir, en el sentido de afirmar, predicar, determinar - mientras que uno de sus últimos escritos inéditos de 1992-1993 se titula "V otkrytom mire" (En un mundo abierto). Escribe en la obra de 1993 editada solo en 2010: 
[...] en la vida real, siempre nos enfrentamos con la presencia del otro: otra persona, no contemplada en el sistema, otra estructura, otro mundo. [Su] función cultural (...) es sumamente grande, y consiste precisamente en el hecho de que este otro invade el 'mundo ordinario' Como un cometa sin ley / En las órbitas calculadas de los astros. (2010: 40, trad. mía) ${ }^{9}$

Al final de su vida Lotman establece de manera definitiva la importancia del "otro" como motor del dinamismo de la cultura, un "otro" que impone un movimiento centrífugo a la semiosfera, desarticulando sus espacios disciplinados, es decir altamente codificados.

\section{CONCLUSIONES}

Hemos comprobado cómo, partiendo de una visión del espacio constructor de relacionalidad, en sus últimos escritos Lotman parece acercarse al concepto de transgresividad como un principio permanente de la cultura contemporánea, sostenida por una lógica de la frontera (Westphal 2007a: 46) con su continuo translimitar creador. En este sentido, el pensador ruso lleva al corazón de la geocrítica la idea de que los textos, para poder ser analizados a través de una metodología "espacio-sensible", necesitan un trabajo de interacción recíproca continua -interacción apta para sacar a la luz las referencias cercanas y lejanas, traducibles e intraducibles, incontrovertibles y marginales, claras y oscuras (es decir, culturalmente indescifrables y por lo tanto provocadoras y "transgresivas").

Por su parte, Westphal, leyendo a Lotman, capta bien que la semiosfera en su conceptualización tardía, a saber, la cultura como sistema complejo marcado por la impredecibilidad es lo que permite al semiólogo ruso complejizar la dinámica espacial bipolar centro/periferia —que caracteriza más los escritos de los años sesenta y setenta- para llegar a una visión plural de la realidad, marcada por "una multitud de opciones y caminos viables" (Westphal 2007a: 32, trad. mía).1

9 Lotman cita los versos 7-8 de la poesía Portret (Il ritratto, 1828) de Aleksandr Pushkin. En la versión en inglés (Lotman 2013: 57) han sido traducidos como sigue: "like a wayward comet among the calculated orbits of the heavenly bodies". 


\section{REFERENCIAS}

Bulgákov, Mijaíl. El maestro y Margarita. Trad. de Valeria Korzeniewski y Alejandro Ariel González. Buenos Aires: Libros del Zorzal, 2015[19661967]).

Burini, Silvia (ed.). “Ecologia' della cultura: le Conversazioni di Jurij Lotman". Conversazioni sulla cultura russa. Florencia-Milán: Studi Bompiani, (2017):7-23.

Clowes, Edith W. Russia on the Edge: Imagined Geographies and Post-Soviet Identity. Ithaca-Londres: Cornell University Press, 2011.

García, Mariano, Punte, María José y Puppo, María Lucía (eds.). Espacios, imágenes y vectores. Desafios actuales de las literaturas comparadas. Buenos Aires: Miño y Dávila editores, 2015.

Gherlone, Laura. Dopo la semiosfera (Con saggi inediti di Jurij M. Lotman). Trad. de Bruno Osimo. Milano-Udine: Mimesis, 2014.

Lotman, Iuri. "Zametki o judozhestvennom prostranstve" (Notas sobre el espacio artístico), Trudy po znakovym sistemam (Semiotika prostranstva i prostranstvo semiotiki) XIX (1986):25-43. Disponible en: https:// dspace.ut.ee/handle/10062/25250 . Universe of the Mind: A Semiotic Theory of Culture. Londres-Nueva York: I.B. Tauris, 1990.

. "O poniatii geograficheskogo prostranstva $\mathrm{v}$ russkij srednevekovyj tekstaj" (Sobre el concepto de espacio geográfico en los textos medievales rusos). Izbrannye stat'i $v$ trej tomaj. 1: Stat'i po semiotike $i$ tipologii kul tury. Tallinn: Aleksandra, 1992a [1965]:407-412. . "Problema judozhestvennogo prostranstva v proze Gogolia" (El problema del espacio artístico en la prosa de Gógol'). Izbrannye stat'i v trej tomaj. 1: Stat'i po semiotike i tipologii kul'tury. Tallinn: Aleksandra, 1992b[1968]:413-447. 
- "Para la construcción de una teoría de la interacción de las culturas (el aspecto semiótico)". La semiosfera. 1: Semiótica de la cultura y del texto. Trad. de Desiderio Navarro. Madrid: Ediciones Cátedra, Valencia: Universitat de València, 1996a [1983]):61-76.

. "Acerca de la semiosfera". La semiosfera. 1: Semiótica de la cultura

$y$ del texto. Trad. de Desiderio Navarro (ed.). Madrid: Ediciones Cátedra, 1996b[1984]):21-42.

. "O 'realizme' Gogolia” (Sobre el 'realismo' de Gógol'). O russkoi literature: stat'i $i$ issledovaniia (1958-1993). San Petersburgo: Iskusstvo-SPB, 1997[1993]:694-711.

. Vnutri mysliashchij mirov (Dentro de los mundos pensantes). Semiosfera. San Petersburgo: Iskusstvo-SPB, 2000a [1996]:150-390.

. "El ensemble artístico como espacio de la vida cotidiana". La semiosfera. 3: Semiótica de las artes y de la cultura. Trad. de Desiderio Navarro (ed.). Madrid: Ediciones Cátedra, 2000b [1974]:113-122.

- "La arquitectura en el contexto de la cultura". La semiosfera. 3: Semiótica de las artes y de la cultura. Trad. de Desiderio Navarro (ed.). Madrid: Ediciones Cátedra, 2000c[1987]:103-112.

. "Besedy o russkoi kul'ture. Tsikl pervyi: Liudi. Sud'by. Byt" (Conversaciones sobre la cultura rusa. Primero ciclo: Gente. Destinos. Vida cotidiana). Vospitanie dushi. San Petersburgo: Iskusstvo-SPB, 2005[1986]:350-413.

. Nepredskazuemyemejanizmy kul'tury (Los mecanismos impredecibles de la cultura). Tallinn: TLU Press, 2010.

. The Unpredictable Workings of Culture. Tallinn: TLU Press, 2013.

Lotman, Iuri et al. "Tesis para el estudio semiótico de las culturas (aplicadas a los textos eslavos)", Entretextos 7(2006[1973]):54-86.

Pilshchikov, Igor (ed.). Urban Semiotics: The City as a Cultural-Historical Phenomenon. Tallinn: Tallinn University Press, 2015.

Semenenko, Aleksei. The Texture of Culture: An Introduction to Yuri Lotman's Semiotic Theory. Nueva York: Palgrave Macmillan, 2012. 
Soja, Edward. "Taking Space Personally”. The Spatial Turn: Interdisciplinary Perspectives. Barney Warf y Santa Arias (eds.). Londres-Nueva York: Routledge, (2009):11-35.

Tally Jr., Robert T. (ed.). Geocritical Explorations: Space, Place, and Mapping in Literary and Cultural Studies. Nueva York: Palgrave Macmillan, 2011.

. The Routledge Handbook of Literature and Space. Londres-Nueva York: Routledge, 2017.

Warf, Barney y Arias, Santa (eds.). "Introduction: The Reinsertion of Space into the Social Sciences and Humanities". The Spatial Turn: Interdisciplinary perspectives. Londres-Nueva York: Routledge, (2009):1-10.

Westphal, Bertrand. "Pour une approche géocritique des textes". La Géocritique: mode d'emploi. Bertrand Westphal (ed.). Limoges: Presses Universitaires de Limoges, (2000):9-40. Disponible en: http://sflgc.org/bibliotheque/westphal-bertrand-pour-une-approchegeocritique-des-textes/

. La géocritique: réel, fiction, espace. París: Les Editions De Minuit, $2007 \mathrm{a}$.

. "Géocritique". La recherche en littérature générale et comparée en France en 2007: bilan et perspectives. Anne Tomiche y Karl Zieger (eds.). Valenciennes: Presses universitaires de Valenciennes, (2007b):325-334.

. "Geocrítica", trad. de Ximena Figueroa Flores y Ninoska Vera Duarte, Bagubra. Revista de literatura y pensamiento desde Valparaíso, 3 (2015):123-131. Disponible en: http://bagubra.ucv.cl/pdf/Edicion3/ Archivos/arc03XimenaFigueroa.pdf . La cage des méridiens: la littérature et l'art contemporain face à la globalisation. París: Les Editions De Minuit, 2016. 
Zivkovic, Yvonne. "bell hooks' Affective Politics of Space and Belonging". The Question of Space: Interventions on the Spatial Turn Between Disciplines. Marijn Nieuwenhuis y David Crouch (eds). Oxford: Rowman \& Littlefield, (2017):145-173. 